\title{
Optimización de la hidrólisis para el tratamiento de residuos lignocelulósicos con enzimas de Aspergillus niger
}

\section{Hydrolysis Optimization for the Lignocellulostic Waste Treatment with Aspergillus niger Enzymes}

\author{
Mylena Alexandra Olivo Urbina ${ }^{1}$, Byron Leoncio Díaz Monroy ${ }^{2}$, Camilo Haro Barroso ${ }^{3}$ y Luis Miguel \\ Borrás Sandoval ${ }^{4}$
}

\begin{abstract}
Resumen
El presente estudio tuvo por objeto optimizar el proceso de hidrólisis enzimática para degradar la celulosa del rastrojo de maíz (Zea mays), utilizando enzimas del Aspergillus niger. Durante la primera fase de la experimentación se determinó el contenido de materia seca, materia orgánica, cenizas, proteína cruda, extracto etéreo, contenido de lignina y celulosa del rastrojo, usándose para su cuantificación los métodos de referencia de la U. Florida 1970. Posteriormente se realizó el pre-secado y molienda del mismo, previo a los procesos de pre-tratamiento álcali y ácido-álcali aplicados, siendo secados a 4 diferentes temperaturas $(45,50,55$ y $\left.60{ }^{\circ} \mathrm{C}\right)$ Los residuos pretratados fueron sometidos a una hidrólisis con celulasas del Aspergillus Niger (39,125 UE) a diferentes $\mathrm{pH}\left(4,0 ; 4,8\right.$ y 5,6), durante 24,48 y $72 \mathrm{~h}$ a $45,50,55$ Y $60{ }^{\circ} \mathrm{C}$ de temperatura; cuantificándose las concentraciones de azúcares reductores liberados durante la digestión. Finalmente se determinó que la hidrólisis del rastrojo sin pretratamiento y secado a $60^{\circ} \mathrm{C}$, a pH de 4,8 por 72 h., tuvo concentraciones elevadas de azúcares reductores, convirtiéndose en una alternativa para su utilización como alimento o biocombustible, posterior a la aplicación de procesos biotecnológicos.
\end{abstract}

Palabras clave: Aspergillus niger, azúcares reductores, biotecnología, hidrólisis enzimática, residuos lignocelulósicos

\begin{abstract}
The present study aimed to optimize the enzymatic hydrolysis process to degrade cellulose from corn stubble (Zea mays), using enzymes from Aspergillus niger. During the first phase of the experimentation, the content of dry matter, organic matter, ash, crude protein, ethereal extract, lignin and cellulose content of the stubble was determined, using the reference methods of the U. Florida 1970 for its quantification. Subsequently the pre-drying and grinding of the same was carried out, prior to the alkali and acid-alkali pre-treatment processes applied, being dried at 4 different temperatures $\left(45,50,55\right.$ and $\left.60{ }^{\circ} \mathrm{C}\right)$. The pretreated residues were subjected to hydrolysis with Aspergillus Niger cellulases (39,125 EU) at different pHs (4.0, 4.8 and 5.6), for 24, 48 and 72 h. at $45,50,55$ and $60{ }^{\circ} \mathrm{C}$ temperature; quantifying the concentrations of reducing sugars released during digestion. Finally, it was determined that the hydrolysis of the stubble without pretreatment and drying at $60{ }^{\circ} \mathrm{C}$, at a pH of 4.8 for $72 \mathrm{~h}$., had high concentrations of reducing sugars, becoming an alternative for its use as food or biofuel, after the application of biotechnological processes.
\end{abstract}

Keywords: Aspergillus niger, reducing sugars, biotechnology, enzymatic hydrolysis, lignocellulosic residues

Recepción: 19-jul-2020

Aceptación: 07-nov-2020

\footnotetext{
${ }^{1}$ Ingeniera en Biotecnología ambiental. Escuela Superior Politécnica de Chimborazo. E-mail: mi lia. lexa28@gmail.com ${ }^{2}$ Doctor en Ciencias veterinarias. Master en Biotecnología. Profesor titular principal de la Escuela Superior Politécnica de Chimborazo, Facultad de Ciencias Pecuarias. E-mail: bdiaz@espoch. edu.ec

${ }^{3}$ Ingeniero en Biotecnología ambiental. Magister en Ingeniería para el Ambiente y el Territorio. Escuela Superior Politécnica de Chimborazo. E-mail: caphasegmail.com

${ }^{4}$ Doctor en Ciencias veterinarias. Ingeniero Zootecnista. Docente. Universidad Pedagógica y Tecnológica de Colombia, UPTC. Grupo de Investigación GIBNA. Colombia. E-mail: luis . borras@upt c . edu . co
} 


\section{Introducción}

En un contexto mundial en el que destaca el continuo aumento de la población, con un creciente ingreso per cápita disponible para consumo, cambios en la dieta y estilos de vida de amplios sectores de la población mundial que ocasionan una mayor ingesta de proteína animal (incluyendo alimentos derivados de la ganadería), se estima que la demanda mundial de productos cárnicos se incremente a un ritmo anual de $1,3 \%$ entre 2007 y 2050 , valor superior al crecimiento anual estimado de $1,1 \%$ para el total de la producción agropecuaria en igual lapso [1]. Este incremento en el consumo de carne en los últimos años lógicamente generará mayor cantidad de emisiones de gases de efecto invernadero y la degradación de los suelos producto del sobrepastoreo y de la producción de alimento para el ganado [2].

En el Ecuador, igual que en el resto del mundo esta producción ganadera depende de su homóloga agrícola como proveedora de fuentes alimenticias para los animales, la cual además genera una alta carga de residuos lignocelulósicos post-cosecha provenientes de los cultivos, entre los que se destaca el maíz, que no son aprovechados; por lo que, una adecuada gestión de los mismos permitiría su aprovechamiento para la elaboración de alimentos alternativos y bioabonos, entre otros productos, mediante la aplicación de biotecnologías de fácil acceso.

Se puede afirmar entonces, que en la actualidad los residuos o desechos agroindustriales y los subproductos, se han convertido en la materia prima de procesos que generan productos con alto valor agregado. Sin embargo, son muchas las limitantes en cuanto a la compleja degradación de la estructura lignocelulósica. Por ello han surgido trabajos e investigaciones que abarcan distintas problemáticas y proponen alternativas de solución hacia la explotación de la biomasa lignocelulósica para este fin [3].

Considerando que los residuos lignocelulósicos poseen importantes cantidades de fibra y celulosa, estos podrían usarse para alimentar a los rumiantes; sin embargo, su baja digestibilidad, los convierte en un desecho a nivel agropecuario [4]. Los nutrientes presentes en follajes y rastrojos podrían ser aprovechados una vez que estos sean sometidos a un tratamiento previo, convirtiéndose en una alternativa para la nutrición del ganado [5].

Uno de estos tratamientos previos de los materiales fibrosos es la hidrólisis enzimática, que al tratarse de la celulosa, esta acción la cumplen las celulasas [6] y [7] pertenecientes a las glicosilhidrolasas, encargadas de la catálisis de los enlaces glucosídicos presentes entre 2 o más hidratos de carbono. Este tipo de enzimas son producidas por varios microorganismos, comúnmente por bacterias y hongos, las de origen fúngico son la más utilizadas debido al poder celulolítico [8], presenta dos módulos globulares independientes, el uno responsable de la hidrólisis; y el otro responsable de la unión con la celulosa. Entre las funciones principales tenemos la de mantener la enzima próxima al sustrato, lograr el reconocimiento con el sustrato, y, por último, la disrupción de la estructura. Existen dos mecanismos para la hidrólisis con dichas enzimas, la de conservación y de inversión de la configuración del carbono anomérico. La hidrólisis del enlace glucosídico es catalizada por dos aminoácidos presentes en el sitio catalítico, donde el primero actúa como un ácido general encargado de la donación de protones, mientras el segundo como un nucleófilo/base. Dependiendo de la posición espacial de estos aminoácidos, la hidrólisis se produce cuando se encuentran a una distancia entre 5,5 ̊ y $10 \AA$ A. Durante la hidrólisis por conservación, la degradación de la celulosa empieza por un proceso de glucosilación para posteriormente generar la deglucosilación, obteniéndose de esta forma el producto hidrolizado. Por otro lado, en el mecanismo de inversión, la hidrólisis se realiza en una sola etapa, donde se genera la incorporación de la molécula de agua entre la base y el azúcar $[4,6]$.

En este contexto, el presente estudio tuvo como objetivo, optimizar la hidrólisis enzimática del rastrojo de maíz, utilizando celulasas de Aspergillus niger. Los residuos tratados podrían convertirse en una alternativa de alimento para el ganado, incrementando su digestibilidad y reduciendo los impactos ambientales causados por la industria ganadera. 


\section{Materiales y métodos}

El presente estudio se realizó en los laboratorios de Biotecnología Animal y de Investigaciones de la Escuela Superior Politécnica de Chimborazo. Durante la experimentación se realizó un diseño multifactorial, teniendo como factores al $\mathrm{pH}$ del medio y el tiempo de hidrólisis enzimática, además de la variable de respuesta que fue la concentración de azúcares reductores. Con los resultados obtenidos se establecieron las condiciones con las que se optimizaría el proceso hidrolítico del rastrojo de maíz.

\subsection{Identificación del rastrojo de maíz utilizado}

La muestra utilizada para la presente investigación se la obtuvo de diferentes productores de maíz de la variedad suave de la ciudad de Riobamba, zona andina de Ecuador, se denomina rastrojo de maíz a la planta completa exceptuando la raíz, luego de la cosecha de la mazorca con grano, cuya longitud o altura oscila entre 0,95 hasta $1,80 \mathrm{~m}$, de naturaleza áspera visiblemente rica en material lignocelulósico, color en tonalidad amarillenta parduzca, generalmente se lo apila pos cosecha para distintos usos como alimento directo del ganado, material combustible para la cocina rural, fertilizante, material de construcción de cercas, etc. Este material fue secado a temperatura ambiente y a la sombra, previo a su utilización en la parte experimental.

\subsection{Caracterización química del rastrojo de maíz}

Se determinó el porcentaje de Materia seca (MS), materia orgánica (MO), cenizas, proteína cruda (PC), extracto etéreo (EE), contenido de lignina y celulosa. El análisis se realizó en el laboratorio de Servicio de Análisis e Investigación en Alimentos del Instituto Nacional de Investigaciones Agropecuarias (INIAP), mediante los métodos citados en la Tabla 1. Posteriormente se realizó el secado del rastrojo a temperatura ambiente y a la sombra, previo a su trituración en un molino Wiley. Finalmente se tamizó la muestra por un tamiz de $3 \mathrm{~mm}$ de diámetro, eliminando los residuos de mayor tamaño.
Tabla 1. Métodos utilizados para la caracterización del rastrojo de maíz

\begin{tabular}{lcc}
\hline Parámetros & Método & Método de referencia \\
\hline Materia seca & MO-LSAIA-01.01 & U. Florida 1970 \\
Materia orgánica & MO-LSAIA-01.02 & U. Florida 1970 \\
Cenizas & MO-LSAIA-01.02 & U. Florida 1970 \\
Proteína cruda & MO-LSAIA-01.04 & U. Florida 1970 \\
Extracto etéreo & MO-LSAIA-01.03 & U. Florida 1970 \\
Humedad & MO-LSAIA-01.01 & U. Florida 1970 \\
Lignina & MO-LSAIA-02.03 & U. Florida 1970 \\
FDA & MO-LSAIA-02.02 & U. Florida 1970 \\
\hline
\end{tabular}

Fuente: Laboratorio de servicio de análisis e investigación en alimentos del INIAP, 2017.

\subsection{Pretratamientos e hidrólisis enzimática del rastrojo de maíz}

Previo al proceso hidrolítico se realizaron tres diferentes pre-tratamientos: En el primero, el rastrojo de maíz fue secado a diferentes temperaturas $(45,50$, 55 y $60{ }^{\circ} \mathrm{C}$ ), evitando cualquier tipo de alteración de la estructura del rastrojo. Tal residuo sin pretratamiento se denomina como blanco, mismo que viene identificado a nivel experimental como P1T1, P1T2 P1T3 y P1T4, donde Tx representa la temperatura a la cual se secó el rastrojo.

El segundo pre-tratamiento (Véase Figura 1), fue de tipo alcalino, mismo que se realizó en un reactor ( $1 \mathrm{~L}$ de capacidad), con $16 \mathrm{~g}$ de rastrojo de maíz y $320 \mathrm{ml}$ de una solución de $\mathrm{NaOH}$ al $2 \%$ (p/v), el cual fue llevado a una temperatura de $80{ }^{\circ} \mathrm{C}$ por un lapso de una hora. Posteriormente el residuo pretratado fue lavado y tamizado (tamiz $38 \mu \mathrm{m}$ ) con agua destilada hasta su neutralidad. Por último, se colocó en una estufa para su secado a 45, 50, 55 y $60{ }^{\circ} \mathrm{C}$ respectivamente. El residuo obtenido es conservado bajo condiciones anhidras previo a la hidrólisis enzimática [5], siendo identificados como P2T1, P2T2, P2T3 y P2T4 (Pre-tratamiento de tipo alcalino, secado a temperatura $\mathrm{Tx}$ ).

El tercero fue de tipo ácido-alcalino (Véase Figura 2), consistió en el pre-tratamiento dentro de un reactor ( $1 \mathrm{~L}$ de capacidad) a $136{ }^{\circ} \mathrm{C}$ durante $30 \mathrm{~min}$, de $30 \mathrm{~g}$ de residuo y $300 \mathrm{ml}$ de $\mathrm{H}_{2} \mathrm{SO}_{4}$ al $1,5 \%(\mathrm{p} / \mathrm{v})$. Posteriormente, el reactor es enfriado en un baño de agua fría hasta alcanzar los $30-35^{\circ} \mathrm{C}$ 
aproximadamente [10]. El residuo pre-tratado es lavado hasta su neutralidad con agua destilada en un tamiz de $38 \mu \mathrm{m}$, para ser secado a una temperatura de $45,50,55$ y $60{ }^{\circ} \mathrm{C}$, durante 4 días. El rastrojo obtenido es sometido al pre-tratamiento alcalino descrito anteriormente. Finalmente, el residuo es identificado con P3T1, P3T2, P3T3 y P3T4 (Pre-tratamiento de tipo ácido-alcalino, secado a temperatura $\mathrm{Tx}$ ).

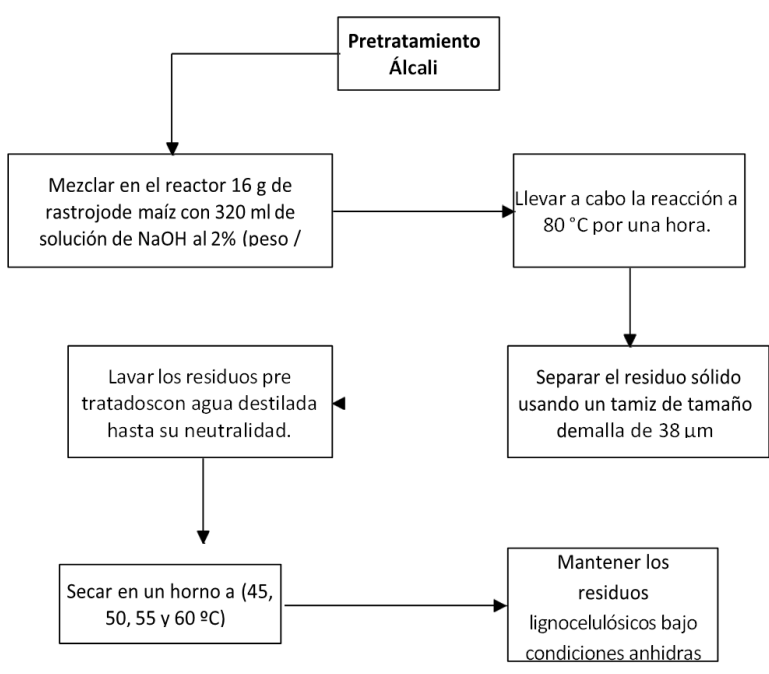

Figura 1. Procedimiento para el Pre-tratamiento alcalino de los residuos lignocelulósicos.

Fuente: Lee, et al. (2015) [9].

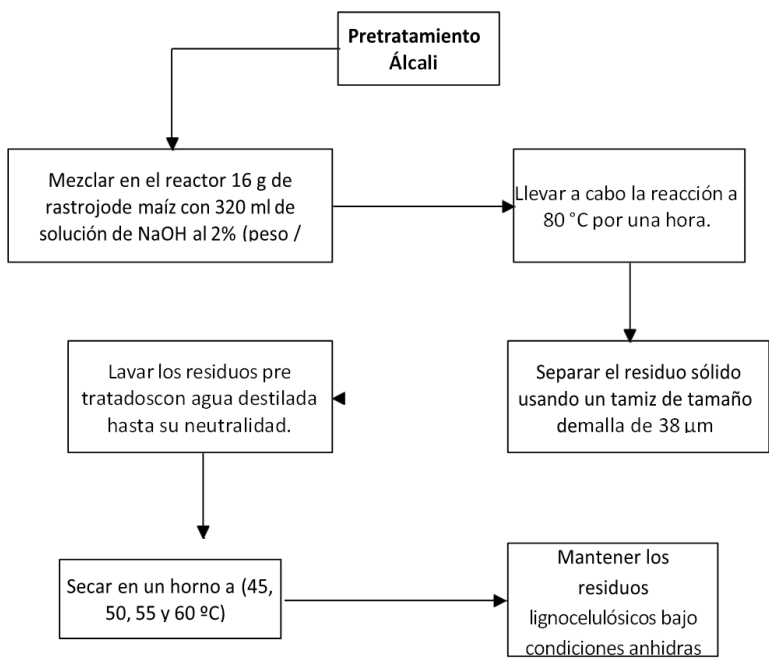

Figura 2. Procedimiento para el pre-tratamiento ácido alcalino de los residuos lignocelulósicos.

Fuente: García et al. (2014) [10].

\subsection{Preparación soluciones buffer pH 4,0; 4,8; y 5,6}

Para la hidrólisis de los residuos pre-tratados se prepararon soluciones buffer de Citrato-Fosfato de concentración de $50 \mathrm{mM}$, necesarios para la solubilización de las enzimas previo al proceso de degradación de la celulosa en la hidrólisis del rastrojo de maíz. Las soluciones de diferentes $\mathrm{pH}$ $(4,0 ; 4,8 ;$ y 5,6$)$ se calcularon mediante el software Buffer Market (2020). Una vez preparadas las mismas, se adicionó azida sódica a una concentración del $0,005 \%(\mathrm{p} / \mathrm{v})$, con la finalidad de inhibir el crecimiento de microorganismos durante la hidrólisis [11].

\subsection{Hidrólisis enzimática}

Luego del pre-tratamiento, se procedió a realizar la hidrólisis enzimática, colocando en matraces Erlenmeyers $1,25 \mathrm{~g}$. de residuo y $62,5 \mathrm{ml}$. de solución buffer de Citrato/Fosfato (pH 4,0; 4,8 y $5,6)$, el cual contiene azida sódica al 0,1\%, según el método de Merck (2018) [12]. para inhibir el desarrollo microbiano que pueda interferir durante la degradación de la celulosa del rastrojo.

Finalmente se incorporaron $0,03125 \mathrm{~g}$ de Celulasas del Aspergillus niger, previo al proceso de incubación en un Orbicult TM Incubator Benchtop Shaker a $50{ }^{\circ}$ C. y 150 RPM durante 24,48 y 72 h. Al finalizar cada intervalo, fueron extraídos $5 \mathrm{ml}$. de la solución hidrolizada. Las muestras obtenidas fueron centrifugadas a $8000 \mathrm{rpm}$. durante $10 \mathrm{~min}$. recuperándose el sobrenadante, necesario para la cuantificación de azúcares reductores a través del método del ácido dinitrosalicilico (DNS) [11].

\subsection{Análisis de azúcares reductores}

Para la determinación de azúcares reductores se construyó una curva de calibración a partir de soluciones estándares de 50, 100, 150, 200, 400, 600 ppm. de glucosa. La preparación tanto de estándares como de muestras, se lo realizó adicionando $0,5 \mathrm{ml}$. de la solución DNS a 0,5 ml. de muestra extraída. Las muestras fueron llevadas a digestión en baño María por 5 minutos, luego del cual se adicionaron $5 \mathrm{ml}$. con agua destilada, dejándolo reaccionar por cerca de 15 min., tiempo en el que se producirá la 
oxido-reducción de los azúcares presentes, según el método de Ávila, et al. (2012) [13].

Finalmente se leen las absorbancias de las muestras a $570 \mathrm{~nm}$. en un espectrofotómetro (THERMO SCIENTIFIC GENESIS 10S UV-VIS). Las concentraciones de azúcares fueron determinadas a partir de la ecuación de regresión lineal obtenida de la curva de calibración.

Finalizada la hidrólisis enzimática, se realizó el análisis estadístico con los resultados obtenidos de las lecturas realizadas, utilizando el software SPSS (Versión 2019); permitiendo determinar las condiciones óptimas en las que se obtendría una mayor degradación de la celulosa presente en el rastrojo de maíz hidrolizado [13].

\section{Resultados y discusión}

Una vez realizada la caracterización del rastrojo de maíz previo al proceso de pre-tratamiento, se obtuvieron los siguientes resultados (Véase Tabla 2).

Tabla 2. Caracterización del rastrojo de maíz

\begin{tabular}{lccc}
\hline Indicador & \multicolumn{1}{c}{ Método } & Unidad & Valores \\
\hline Humedad & MO-LSAIA-01.01 & $\%$ & 34.29 \\
Cenizas & MO-LSAIA-01.02 & $\%$ & 10.85 \\
Extracto Etéreo & MO-LSAIA-01.02 & $\%$ & 0.67 \\
Proteína cruda & MO-LSAIA-01.04 & $\%$ & 5.44 \\
Materia seca & MO-LSAIA-01.03 & $\%$ & 65.71 \\
F.D.A & MO-LSAIA-01.01 & $\%$ & 47.26 \\
Celulosa & MO-LSAIA-02.03 & $\%$ & 40.64 \\
Lignina & MO-LSAIA-02.02 & $\%$ & 6.62 \\
\hline
\end{tabular}

Fuente: Laboratorio de servicio de análisis e investigación en alimentos del INIAP (2020).

Como se observa en la Tabla 2, la caracterización química del rastrojo muestra un contenido representativo de celulosa $(40,64 \%)$, lignina $(6,62 \%)$ y Fibra Detergente Ácida $(47,26)$, sin descartar la concentración de proteína y de cenizas que se encuentran en torno al 5,44 y $10,85 \%$. respectivamente, confirmando así su potencial utilización como materia prima para la obtención de bioetanol o como alimento para el ganado previo a un proceso de hidrólisis. El contenido de lignina responsable de la rigidez del rastrojo $(6,62 \%)$, es menor al observado en plantas herbáceas y en arbustos, valor que bordea el 20
$\%$ [14], las diferentes propiedades físicas y químicas de la lignina pueden tener varios efectos sobre la hidrólisis enzimática de sustratos lignocelulósicos [15], mientras que la Fibra Detergente Ácida (FDA) es igual al 50\%. Los forrajes de buena calidad presentan valores superiores al $70 \%$ de FDA, un pretratamiento o una hidrólisis enzimática del residuo mejorarían la calidad del rastrojo del maíz previo a su utilización como alimento para el ganado, incrementando la digestibilidad [16], aunque hasta ahora, la sacarificación de residuos lignocelulósicos mediante hidrólisis enzimática produce bajos rendimientos, lo cual dificulta su uso a nivel industrial [17].

Durante el pre-tratamiento aplicado al rastrojo de maíz se pudo observar que de acuerdo al proceso álcali y ácido-álcali, la cantidad de sustrato utilizado se reduce debido a la deslignificación oxidativa que permite el rompimiento y la solubilización de la lignina, con la finalidad de incrementar la accesibilidad de la enzima a la celulosa durante la hidrólisis [18]. Pues, el efecto del pretratamiento en materiales lignocelulósicos ha sido reconocido en el tiempo, su propósito es remover la lignina y la hemicelulosa, reducir la cristalinidad de la celulosa y aumentar la porosidad del material, aunque las principales dificultades al realizar hidrólisis enzimática de biomasa lignocelulósica están relacionadas con la baja actividad específica de las enzimas actualmente disponibles, lo que conlleva el empleo de altas dosis de celulasas, y con la propia naturaleza de la lignocelulosa, es por este último inconveniente que el pretratamiento es una etapa crucial en los procesos de aprovechamiento de residuos lignocelulósicos mediante hidrólisis enzimática [19]. El pretratamiento de las materias primas lignocelulósicas se realiza bajo ciertas condiciones de severidad, lo que suele provocar degradación de la lignina y de los azúcares hemicelulósicos y/o celulósicos, formándose compuestos tóxicos o inhibidores que pueden influir negativamente en las etapas posteriores de hidrólisis enzimática y fermentación [20] citado por Paniagua, (2020) [21]. Entre los principales factores que afectan a la hidrólisis enzimática de la celulosa, se encuentran: la naturaleza del sustrato y el tipo de pretratamiento al que ha sido sometido, la actividad de las celulasas y las condiciones de la reacción enzimática (principalmente $\mathrm{pH}$, temperatura y tiempo) 
[22], por lo que para mejorar el rendimiento y la velocidad de la etapa de hidrólisis enzimática, los trabajos publicados se enfocan en la optimización del proceso de hidrólisis y en el aumento de la actividad enzimática. Relacionando la masa del residuo previo y posterior al proceso de pre-tratamiento, se obtuvo la reducción de la misma en las proporciones que se indican en la Tabla 3.

Tabla 3. Porcentaje de reducción del rastrojo pre-tratado

\begin{tabular}{lccc}
\hline Pre-tratamiento & Masa inicial (g) & Masa final (g) & \% de reducción \\
\hline Álcali & 16 & 6,03 & 62,34 \\
Ácido-álcali & 30 & 10,99 & 63,40 \\
\hline
\end{tabular}

Fuente: Autora y resultados experimentales (2020).

De acuerdo a los resultados obtenidos, los residuos tratados mediante el proceso ácido-álcali presentan un mayor porcentaje de reducción debido principalmente a las reacciones generadas tanto en el medio ácido como en el medio alcalino, lo cual incide en una mayor solubilización de la lignina y mayor degradación de la celulosa y hemicelulosa [23].

Una vez realizado el pre-tratamiento y la hidrólisis con enzimas de Aspergillus Niger, se observó que el rastrojo de maíz sin pre-tratamiento, hidrolizado a $\mathrm{pH}$ de 4,8 por 72 horas, presentó una mayor concentración de azúcares reductores si se compara con los residuos pre-tratados en condiciones alcalinas y ácido-alcalinas. Además, los residuos secados a $60{ }^{\circ} \mathrm{C}$, presentaron una mayor concentración de azúcares en el sobrenadante a diferencia de los otros que fueron secados a las diferentes temperaturas citadas $\left(45,50\right.$ y $\left.55^{\circ} \mathrm{C}\right)$ Los indicadores anteriormente citados fueron determinados como las condiciones óptimas para la hidrólisis enzimática (Véase Tabla 4), lo cual contrasta con las condiciones óptimas para la hidrólisis de cáscaras de plátano, que fueron $35^{\circ} \mathrm{C}$, 5 días, y pH de 5,5 [24].

Tabla 4. Condiciones óptimas para la hidrólisis enzimática

\begin{tabular}{lccc}
\hline Pre-tratamiento & $\begin{array}{c}\text { Temp. de } \\
\text { secado }\end{array}$ & $\begin{array}{c}\mathbf{p H} \text { de } \\
\text { hidrólisis }\end{array}$ & $\begin{array}{c}\text { Tiempo de } \\
\text { hidrólisis }\end{array}$ \\
\hline Sin pre-tratamiento & $60{ }^{\circ} \mathrm{C}$ & 4,8 & 72 horas \\
\hline
\end{tabular}

Fuente: Autora y resultados del trabajo experimental (2021).
Los pre-tratamientos alcalino y ácido-alcalino aplicados al rastrojo, estarían contribuyendo con la degradación de las cadenas celulósicas en azúcares reductores durante su digestión alcalina y acida-alcalina; por lo que, durante la neutralización de las muestras, se eliminarían las mismas en el lavado. Ante esto, la hidrólisis de los residuos sin pre-tratamiento previo, presentaría mayores concentraciones de azúcares reductores en comparación a los demás tratamientos. De acuerdo a Narciso (2007) [25], la hidrólisis enzimática del bagazo de caña sin pre-tratamiento previo, obtiene una mayor concentración de azúcares reductores; por lo que al ser el maíz una planta de la misma familia que la caña azucarera, tendría un comportamiento similar durante un proceso hidrolítico, favoreciendo la conservación de los azúcares en el medio acuoso; por lo que, el azúcar obtenido durante el pretratamiento del rastrojo de maíz, se estaría eliminando durante la neutralización con agua destilada.

Las concentraciones de azúcares en el sobrenadante de los residuos hidrolizados a $\mathrm{pH} 4,8$ durante 72 horas, presentaron valores que varían entre 250 hasta 480 ppm. Las altas concentraciones de azúcares detectadas en los residuos sin pre-tratamiento y sometidos a un pre-tratamiento alcalino (Véase Figura 2), estarían relacionadas tanto con la efectividad de las enzimas ( $\mathrm{pH}$ en torno a 5), como con la composición química del rastrojo, debido a que el contenido de lignina se encuentra por debajo del $6,62 \%$. El bajo contenido de lignina favorecería el accionar de las celulasas sobre las estructuras celulósicas, hidrolizando tanto la celulosa como la hemicelulosa presente en los residuos. Según [22], existe un alto efecto sinérgico que se produce entre las endoglucanasas y las celobiohidrolasas, el cual es necesario para que haya una eficiente hidrólisis de la celulosa. Además, los productos liberados por las endoglucanasas y celobiohidrolasas, especialmente la celobiosa, producen un fuerte efecto inhibidor en la actividad de ambas enzimas, por lo que se requiere la presencia de $\beta$-glucosidasas, que degraden la celobiosa, para que la hidrólisis transcurra de manera eficaz [22]. Por tanto, es entendible que si el complejo de celulasas no tiene suficiente actividad de $\beta$-glucosidasa, será necesaria una adición externa para aumentar la eficiencia enzimática. 


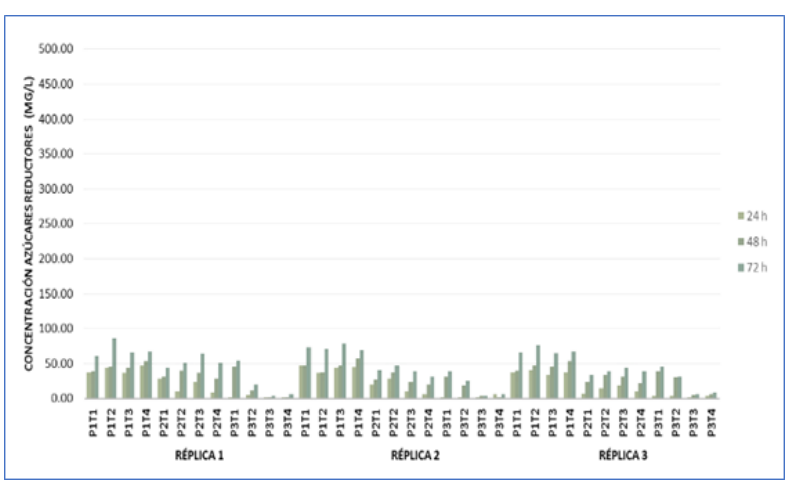

Figura 3. Concentración de Azúcares reductores vs Tratamiento aplicado a pH 4. Pretratamiento aplicado a una determinada temperatura (PxTx).

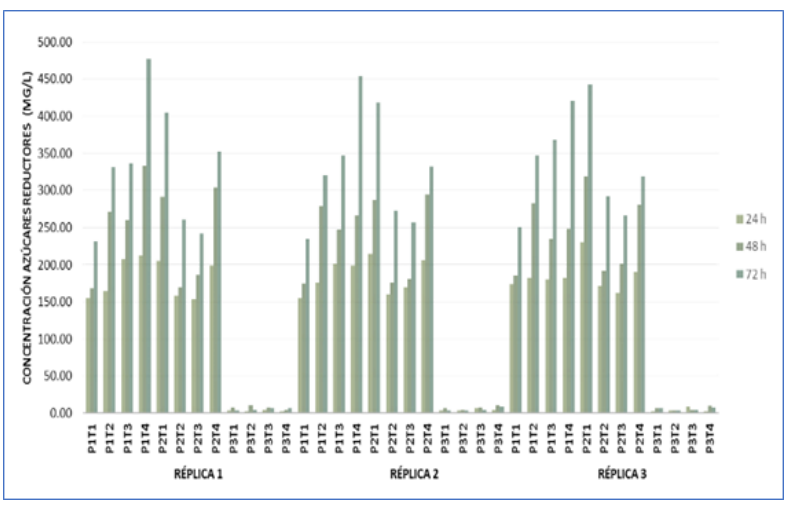

Figura 4. Concentración de Azúcares reductores vs Tratamiento aplicado a pH 4,8. Pretratamiento aplicado a una determinada temperatura (PxTx).

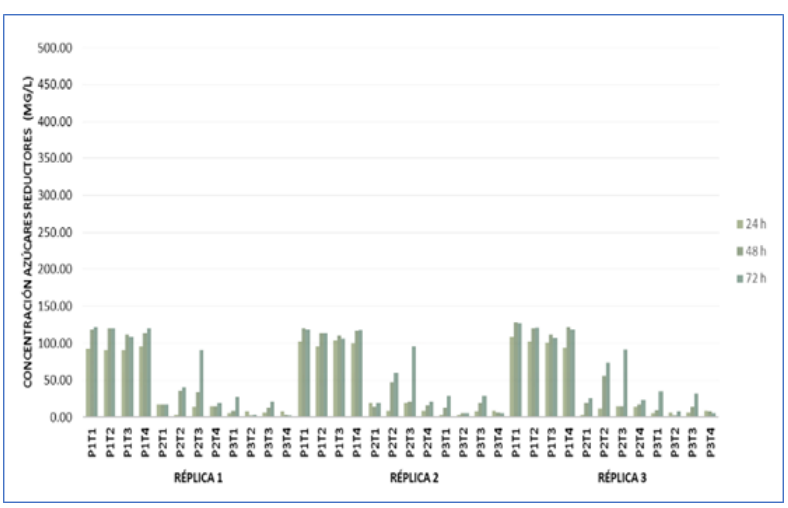

Figura 5. Concentración de Azúcares reductores vs Tratamiento aplicado a pH 5,6. Pretratamiento aplicado a una determinada temperatura (PxTx).

El pretratamiento alcalino aplicado al rastrojo de maíz, generó un efecto sobre la lignina, toda vez que el hidróxido de Sodio $(\mathrm{NaOH})$ contribuiría con la solubilización de la misma, favoreciendo el accionar de las celulasas sobre la el rastrojo pretratado.
La hidrólisis química de residuos lignocelulósicos en presencia de $\mathrm{NaOH}$ a bajas concentraciones (Solución al 5\%), incrementaría la solubilidad de la lignina en residuos que contengan entre el $10 \mathrm{y}$ el $18 \%$ de la misma, siendo más efectiva que el $\mathrm{Ca}(\mathrm{OH})_{2}$ [26]. El accionar del $\mathrm{NaOH}$ sobre la lignina presente en el rastrojo, permitiría la conservación de azúcares en la celulosa; por lo que, estos podrían liberarse durante la hidrólisis enzimática (Véase Figura 2).

Contrario a lo observado en la hidrólisis enzimática del rastrojo sometido a un pretratamiento alcalino, la efectuada con los residuos pretratados con un proceso ácido-álcali, no mostraron resultados importantes, toda vez que el pretratamiento antes señalado, habría degradado en mayor medida los enlaces glucosídicos y las estructuras lignocelulósicas, ocasionando una mayor solubilización de los azúcares obtenidos durante la neutralización del rastrojo pretratado. El pretratamiento ácido-álcali reduciría entre el 80 y el $95 \%$. de los azúcares presentes en el rastrojo de maíz, debido a la solubilización de la lignina y a la pérdida de los azúcares durante el lavado[23].

De acuerdo a la prueba de efectos entre variables (Véase Tabla 5), se evidenció que la correlación entre las variables (pre-tratamientos, tiempos, temperaturas y $\mathrm{pH}$ ), muestran diferencias significativas en la mayoría de las interacciones, lo cual indicaría que las concentraciones de azúcares reductores de los tratamientos difieren entre sí; sin embargo, la interacción entre los tiempos de incubación y las temperaturas de secado del sustrato, generaría poca significancia; por lo que, las concentraciones de azúcares durante la hidrólisis no se verían afectadas por las temperaturas de secado de los residuos.

De acuerdo al análisis de variables se determinó la existencia de diferencias significativas entre los tipos de pretratamiento, el $\mathrm{pH}$ de hidrólisis y los tiempos de incubación ( $\mathrm{p}<0.05$ ); por lo que al realizar el análisis de medias, la hidrólisis de los residuos sin pretratamiento, a $\mathrm{pH} 4,8$ y 72 horas de incubación, fue la que presentó mejores resultados; por lo que, la hidrólisis enzimática bajo estas condiciones, permitirían optimizar el rastrojo de maíz como alimento para el ganado o como fuente 
Tabla 5. Pruebas de efectos entre variables. Variable dependiente: concentración de azúcares reductores

\begin{tabular}{lccc}
\hline Origen & gl & Sig. & Nivel de Sig. \\
\hline Modelo & 108 &, 000 & $* * *$ \\
Pre-tratamientos & 2 &, 000 & $* * *$ \\
Tiempos & 2 &, 000 & $* * *$ \\
Temperatura & 3 &, 000 & $* * *$ \\
$\mathrm{pH}$ & 2 &, 000 & $* * *$ \\
Tratamiento * tiempos & 4 &, 000 & $* * *$ \\
Tratamiento * temperatura & 6 &, 000 & $* * *$ \\
Tratamiento * pH & 4 &, 000 & $* * *$ \\
Tiempos * temperatura & 6 &, 013 & NS \\
Tiempos * pH & 4 &, 000 & $* * *$ \\
Temperatura * pH & 6 &, 000 & $* * *$ \\
Tratamiento * tiempos * temperatura & 12 &, 000 & $* * *$ \\
Tratamiento * tiempos * pH & 8 &, 000 & $* * *$ \\
Tratamiento * temperatura * pH & 12 &, 000 & $* * *$ \\
Tiempos * temperatura * pH & 12 &, 000 & $* * *$ \\
Tratamiento * tiempos * temperatura * pH & 24 &, 000 & $* * *$ \\
Error & 216 & & \\
Total & 324 & & \\
\hline
\end{tabular}

Nota: NS No significativo. *** Significativo.

Fuente: Autora (2020).

de producción de bioetanol.

Los análisis de varianza (Anova), se efectuaron para determinar las condiciones en las que se produciría una mayor liberación de azúcares reductores en cada uno de los tratamientos estudiados, esto es en relación al pre-tratamiento aplicado, el pH de la hidrólisis, la temperatura de secado de los residuos, y el tiempo de incubación, observándose el siguiente comportamiento.

Tabla 6. Anova de los pre-tratamientos. Variable dependiente: concentración de azúcares reductores

\begin{tabular}{lcccccc}
\hline & $\begin{array}{c}\text { Suma de } \\
\text { cuadrados }\end{array}$ & gl & $\begin{array}{c}\text { Media } \\
\text { cuadrática }\end{array}$ & F & Sig. & $\begin{array}{c}\text { Nivel de } \\
\text { Sig. }\end{array}$ \\
\hline $\begin{array}{l}\text { Entre } \\
\text { grupos }\end{array}$ & 970542,448 & 2 & $485271,22462,732$ &, 000 & $* * *$ \\
$\begin{array}{l}\text { Dentro de } \\
\text { grupos }\end{array}$ & 2483139,974 & 321 & 7735,639 & & & \\
Total & 3453682,422 & 323 & & & & \\
\hline
\end{tabular}

Fuente: Autora (2020).

Con este análisis (Tablas 6 y 7), se evidenció un nivel de significancia inferior a 0,001 ; lo que indica la existencia de diferencias altamente significativas
Tabla 7. Medias de las concentraciones de azúcares reductores en relación con los pre-tratamientos (Tukey $\mathrm{B}^{a, b}$

\begin{tabular}{lcccc}
\hline \multirow{2}{*}{ Pre-tratamientos } & $\mathrm{N}$ & \multicolumn{3}{c}{ Subconjunto } \\
\cline { 3 - 5 } & & 1 & 2 & 3 \\
\hline pre-tratamiento ácido-álcali & 108 & 9,9306 & & \\
pre-tratamiento álcali & 108 & & 102,4653 & \\
sin pre-tratamiento & 108 & & & 140,2083 \\
\hline
\end{tabular}

Fuente: Autora (2020).

entre las medias de las concentraciones de azúcares reductores de los diferentes tratamientos, siendo el rastrojo de maíz sin pre-tratamiento el que mejor respuesta presenta con relación a los residuos pretratados; sin embargo, la media de las concentraciones del pre-tratamiento alcalino es representativo.

Tabla 8. Anova de los tiempos de incubación. Variable dependiente: concentración de azúcares reductores

\begin{tabular}{lcccccc}
\hline & $\begin{array}{c}\text { Suma de } \\
\text { cuadrados }\end{array}$ & gl & $\begin{array}{c}\text { Media } \\
\text { cuadrática }\end{array}$ & F & Sig. & $\begin{array}{c}\text { Nivel de } \\
\text { Sig. }\end{array}$ \\
\hline $\begin{array}{l}\text { Entre } \\
\text { grupos }\end{array}$ & 129483,68 & 2 & 64741,84 & 6,25 & 0,002 & $* *$ \\
$\begin{array}{l}\text { Dentro } \\
\text { de grupos }\end{array}$ & 3324198,74 & 321 & 10355,75 & & & \\
$\begin{array}{l}\text { Total } \\
3453682,42\end{array}$ & 323 & & & & \\
\hline
\end{tabular}

Fuente: Autora (2020).

Tabla 9. Medias de las concentraciones en relación con los diferentes tiempos (Tukey $\mathrm{B}^{a, b}$ )

\begin{tabular}{lccc}
\hline \multirow{2}{*}{ Tiempos } & $\mathrm{N}$ & \multicolumn{2}{c}{ Subconjunto para alfa $=0,05$} \\
\cline { 3 - 4 } & & 1 & 2 \\
\hline 24 & 108 & 60,8912 & \\
48 & 108 & 82,0023 & 82,0023 \\
72 & 108 & & 109,7106 \\
\hline
\end{tabular}

Fuente: Autora (2020).

Con respecto al Anova de los tiempos de incubación (Tablas 8 y 9), se evidenció que el nivel de significancia es menor a 0,01 , lo que indica que la diferencia entre las medias de las concentraciones de azúcares reductores obtenida para los grupos en los subconjuntos homogéneos son significativas, existiendo cierta similitud entre las medias obtenidas a las 24 y 48 horas como también entre las 48 y 72 horas de incubación, evidenciándose una mayor presencia de azúcares al finalizar la experimentación, 
es decir, el tiempo óptimo de incubación sería a las 72 horas.

Tabla 10. Anova de las temperaturas de secado. Variable dependiente: concentración de azúcares reductores

\begin{tabular}{lcccccc}
\hline & $\begin{array}{c}\text { Suma de } \\
\text { cuadrados }\end{array}$ & gl & $\begin{array}{c}\text { Media } \\
\text { cuadrática }\end{array}$ & F & Sig. & $\begin{array}{c}\text { Nivel de } \\
\text { Sig. }\end{array}$ \\
$\begin{array}{l}\text { Entre } \\
\text { grupos }\end{array}$ & 4668,72 & 3 & 1556,242 & 0,144 & 0,933 & NS \\
$\begin{array}{l}\text { Dentro de } \\
\text { grupos }\end{array}$ & 3449013,70 & 320 & 10778,168 & & & \\
Total & 3453682,42 & 323 & & & & \\
\hline
\end{tabular}

Fuente: Autora (2020).

Tabla 11. Medias de las concentraciones en relación con las diferentes temperaturas (Tukey $\mathrm{B}^{a, b}$ )

\begin{tabular}{lcc}
\hline \multirow{2}{*}{ Temperatura $\left({ }^{\circ} \mathrm{C}\right)$} & $\mathrm{N}$ & Subconjunto para $\alpha=0,05$ \\
\cline { 3 - 3 } & & 1 \\
\hline 55 & 81 & 80,6636 \\
50 & 81 & 81,0494 \\
45 & 81 & 85,0154 \\
60 & 81 & 90,0772 \\
\hline
\end{tabular}

Fuente: Autora (2020).

En relación al Anova de las temperaturas de secado del rastrojo (Tablas 10 y 11), con o sin pretratamiento se observa que el nivel de significancia es superior a 0,05 , lo que indica que la diferencia entre las medias de las concentraciones de azúcares reductores obtenida para los grupos en los subconjuntos homogéneos no son significativas, por lo que el secado del residuo a diferentes temperaturas (45, 50,55 y $60{ }^{\circ} \mathrm{C}$ ) no incidiría sobre el incremento de las concentraciones de azúcares en los diferentes tratamientos.

Tabla 12. Anova de los $\mathrm{pH}$ de los diferentes tratamientos. Variable dependiente: concentración de azúcares reductores

\begin{tabular}{lcccccc}
\hline & $\begin{array}{c}\text { Suma de } \\
\text { cuadrados }\end{array}$ & gl & $\begin{array}{c}\text { Media } \\
\text { cuadrática }\end{array}$ & F & Sig. & $\begin{array}{c}\text { Nivel de } \\
\text { Sig. }\end{array}$ \\
\hline $\begin{array}{l}\text { Entre } \\
\text { grupos }\end{array}$ & 1227219,56 & 2 & 613609,78 & 88,46 &, 000 & $* * *$ \\
$\begin{array}{l}\text { Dentro de } \\
\text { grupos }\end{array}$ & 2226462,86 & 321 & 6936,02 & & & \\
Total & 3453682,42 & 323 & & & & \\
\hline
\end{tabular}

Fuente: Autora (2020).
Tabla 13. Medias de las concentraciones en relación con los diferentes $\mathrm{pH}$ (Tukey $\mathrm{B}^{a, b}$ )

\begin{tabular}{ccccc}
\hline \multirow{2}{*}{$\mathrm{pH}$} & $\mathrm{N}$ & \multicolumn{3}{c}{ Subconjunto } \\
\cline { 3 - 5 } & & 1 & 2 & 3 \\
\hline 4,0 & 108 & 31,9792 & & \\
5,6 & 108 & & 50,0116 & \\
4,8 & 108 & & & 170,6134 \\
\hline
\end{tabular}

Fuente: Autora (2020).

Del Anova realizado sobre los valores de $\mathrm{pH}$ utilizados durante la hidrólisis enzimática (Tablas 12 y 13), se estableció que el nivel de significancia es menor a 0,001 , lo que indica que la diferencia entre las medias de las concentraciones de azúcares reductores obtenida para los grupos en los subconjuntos son significativas, es decir, los valores obtenidos de las medias de las concentración de azúcares a diferentes $\mathrm{pH}(4,0 ; 4,8$ y 5,6), difieren entre sí, sin embargo, de acuerdo a los resultados mostrados, el pH óptimo en el que se obtiene una mayor concentración de azúcares reductores es a 4,8 .

Al realizar un análisis gráfico de las medias marginales estimadas de la concentración de azúcares reductores en relación a las distintas variables evaluadas, tenemos lo siguiente:

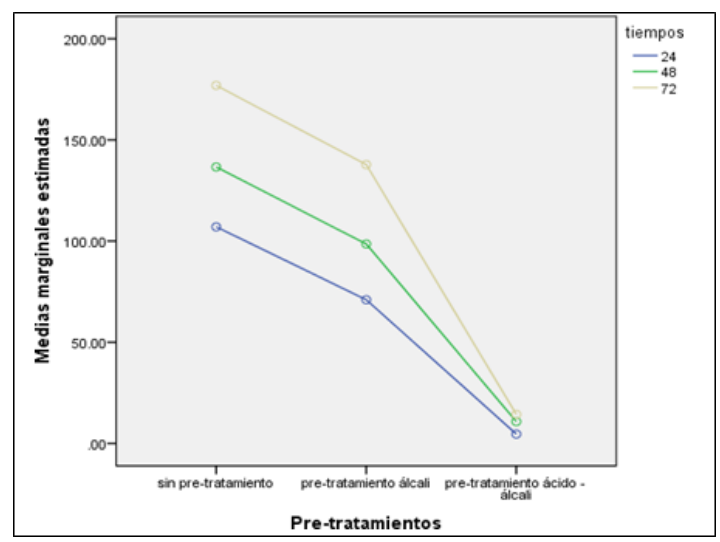

Figura 6. Medias marginales estimadas de concentración en relación a: pre-tratamientos vs tiempos.

Fuente: Autora (2020).

Del análisis efectuado entre las medias marginales de las concentraciones y la relación pre-tratamiento versus tiempo, se observa que la utilización del rastrojo de maíz sin pre-tratamiento generó una mayor producción de azúcares a las 72 horas de incubación en contraste con los residuos pre-tratados 
en un medio alcalino y alcalino-ácido; sin embargo la producción de azúcares reductores a partir de los residuos pre-tratados mediante el proceso alcalino, alcanzó una importante concentración, que sería ligeramente inferior a los obtenidos con el residuo sin pre-tratamiento (Véase Figura 4).

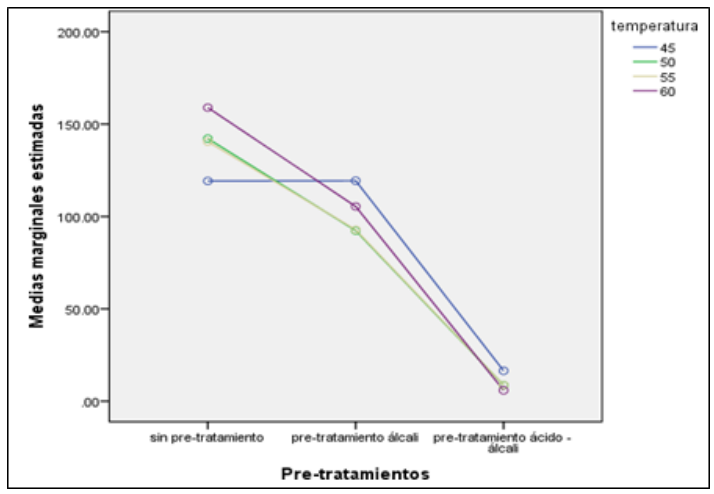

Figura 7. Medias marginales estimadas de concentración en relación a: pre-tratamientos vs temperatura.

Fuente: Autora (2020).

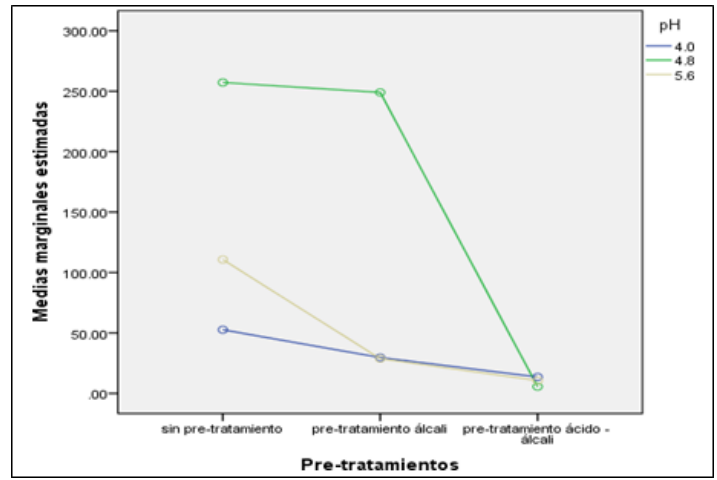

Figura 8. Medias marginales estimadas de concentración en relación a (pre-tratamientos vs $\mathrm{pH}$ ).

Fuente: Autora (2020).

Como se evidencia en el Figura 5, las concentraciones de azúcares versus los pre-tratamientos y las temperaturas de secado del residuo, indica que no existen diferencias significativas entre las temperaturas de secado, por lo que se infiere que la hidrólisis de los residuos únicamente depende del tipo de pretratamiento aplicado durante la experimentación.

Con respecto a la relación entre las concentraciones de azúcares versus los pre-tratamientos y $\mathrm{pH}$ utilizados durante la hidrólisis (Figura 6), se observa que un $\mathrm{pH}$ en torno a 4,8 produce una mejor actividad enzimática lo cual estaría relacionado con la concentración de azúcares obtenidos, por lo que un
pH 4 y 5,6 no incidirían mayormente sobre el proceso de degradación del rastrojo de maíz, por lo que las concentraciones serían bajas siempre que el $\mathrm{pH}$ sea distinto a 4,8 ; todo esto se debe a la proximidad al rango de eficiencia que presentan las enzimas.

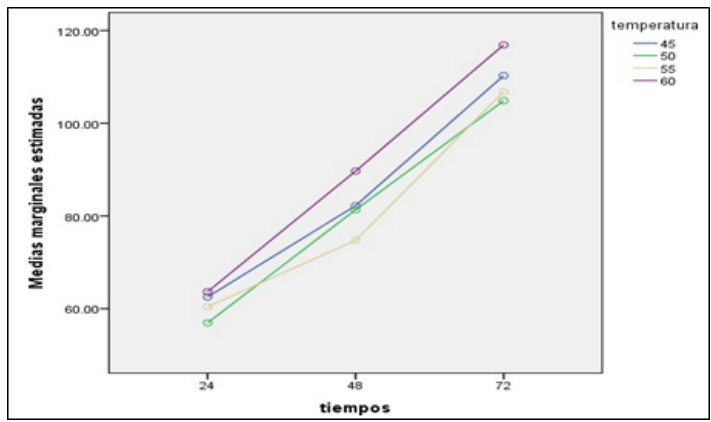

Figura 9. Medias marginales estimadas de concentración en relación a: tiempos vs temperaturas.

Fuente: Autora (2020).

Como se observa en el Figura 7, la relación entre las concentraciones de azúcares versus las temperaturas de secado del rastrojo pre-tratado, no presenta diferencias significativas, mientras que el tiempo de incubación genera una mayor concentración de azúcares reductores a las 72 horas, el cual sería el tiempo óptimo para que se generen concentraciones representativas de azúcares reductores durante la hidrólisis enzimática.

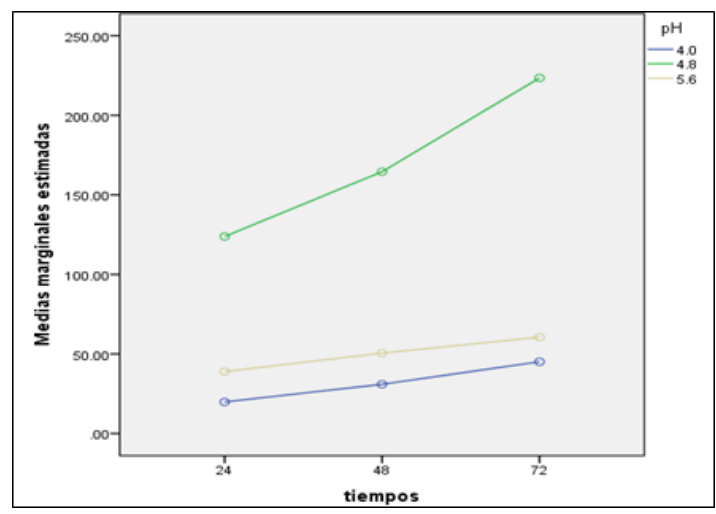

Figura 10. Medias marginales estimadas de concentración en relación a: tiempos vs $\mathrm{pH}$.

Fuente: Autora (2020).

En el análisis de las medias marginales de las concentraciones de azúcares en función de la relación entre el pH y los tiempos de incubación durante la hidrólisis, se observa que a un $\mathrm{pH}$ de 4,8 se produce una mayor degradación del rastrojo de maíz y que conforme avanza el tiempo de incubación, la 
concentración de azúcares reductores tiende a incrementarse. Además, se pudo constatar que a un $\mathrm{pH}$ 4 y 5,6 , y a tiempos inferiores a las 72 horas, las medias marginales de las concentraciones no serían representativas, todo esto debido a la proximidad que tendría el $\mathrm{pH} 4,8$ al óptimo requerido para la actividad de las enzimas (Véase Figura 8).

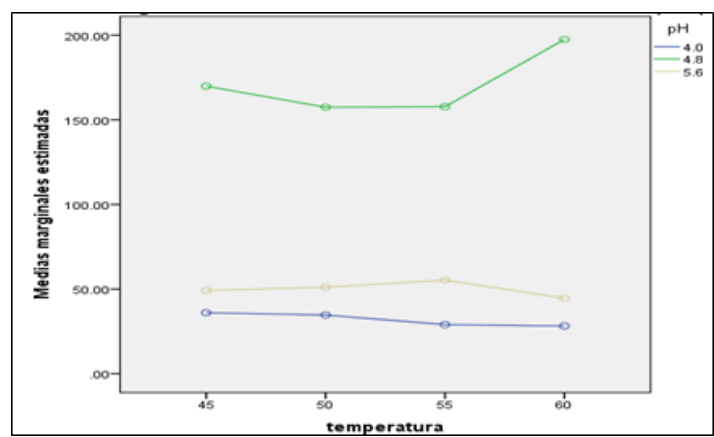

Figura 11. Medias marginales estimadas de concentración en relación a: temperaturas vs $\mathrm{pH}$.

Fuente: Autora (2020).

Como se indica en el Figura 9, la relación entre las medias marginales de las concentraciones de azúcares con respecto al $\mathrm{pH}$ y las temperaturas de secado del rastrojo de maíz, confirman lo indicado anteriormente, donde el pH óptimo de la hidrólisis es de 4,8 mientras que la temperatura de secado no generó variaciones significativas; sin embargo a un $\mathrm{pH}$ de 4,8 , los residuos secados a $60{ }^{\circ} \mathrm{C}$ provocaron un ligero incremento en las concentraciones de azúcares, lo cual no difiere mayormente con los valores alcanzados por los demás tratamientos, donde el rastrojo utilizado fue secado a 45,50 y $55^{\circ} \mathrm{C}$.

Frente a los resultados y a las gráficas analizadas anteriormente se pudo corroborar que las mejores condiciones en las que se produjo la hidrólisis enzimática del rastrojo de maíz, se dieron a un $\mathrm{pH}$ de 4,8 y un tiempo de incubación de 72 horas; sin embargo, en relación al pre-tratamiento aplicado, se evidenció que la mayor concentración de azúcares reductores se obtuvo de los residuos que no fueron sometidos a un pre-tratamiento, y que fueron secados a una temperatura de $60{ }^{\circ} \mathrm{C}$.

\section{Conclusiones}

La optimización de la hidrólisis enzimática del rastrojo de maíz, se logró realizando una trituración, tamizaje y secado a $60^{\circ} \mathrm{C}$ e hidrolizándolo a un $\mathrm{pH}$ de 4,8 durante 72 horas de incubación, obteniéndose concentraciones de azúcares reductores en torno a los 480 ppm; sin embargo, la hidrólisis del rastrojo sometido a un pre-tratamiento alcalino, secado a $45^{\circ} \mathrm{C}$. y a pH de 4,8 , generó concentraciones cercanas a las $450 \mathrm{ppm}$, luego de 72 horas de incubación, pudiéndose aprovechar tales residuos para la producción de bioetanol y como alimento del ganado, previo a una cuantificación inicial del contenido de lignina.

El contenido de celulosa ubicado en 40,64\%, la fibra detergente ácida de $47,26 \%$, una proteína cruda de $5,44 \%$ y principalmente la lignina en alrededor del 6,62\% considerada como baja en relación a otras plantas herbáceas; hacen que el aprovechamiento del rastrojo de maíz, como fuente de carbohidratos sería importante en la industria alimentaria animal, luego de efectuada una hidrólisis enzimática.

La aplicación del pretratamiento ácido-álcali, favorecería la degradación de las estructuras lignocelulósicas del rastrojo; sin embargo, la acción del $\mathrm{NaOH}$ y del $\mathrm{H}_{2} \mathrm{SO}_{4}$, disminuiría la disponibilidad de celulosa en la hidrólisis enzimática, toda vez que durante la neutralización, se solubilizarían los azúcares degradados durante la digestión efectuada.

\section{Referencias}

[1] M. Acevedo, M. castillo y J. Quijano. "Industria de ganadería de carne. Estudios industriales, orientación estratégica para la toma de decisiones" [online]. ESPAE, ESPOL, Ecuador, 2016.

[2] E. Jacobo, N. Cadaviz, M. Vecchio, y A. Rodriguez. "Estimación del balance de gases de efecto invernadero en sistemas de producción ganadera de la cuenca del río Salado," AGRISCIENTIA, Vol. 37, p. 15-32, 2020. doi: 10.31047/1668.298x.v37.n1.27514.

[3] M. Malagón, C. Garay y N. Peña. "Obtención de bioetanol a partir de residuos lignocelulósicos" [online]. Fundación Universidad de América, Semilleros Formación Investigativa Vol. 3, núm 1, p. 69-76, enero-diciembre 2017. 
[4] C. R. Molano, D. Fonseca-López, L. E. N. Monroy, A. E. S. López, J.L.H. Concha, I.D.O. Ramírez, N.T. Lagos, "Caracterización nutricional y de producción de biomasa de Sambucus peruviana, Sambucus nigra y Morus alba en un banco forrajero," Ciencia en Desarrollo, Vol. 10, p. 23-32, 2019. doi: 10.19053/01217488.v10.n2.2019.9098.

[5] A. Galindo, G. Domínguez, R. Arteaga, y G. Salazar. "Mitigación y adaptación al cambio climático mediante la implementación de modelos integrados para el manejo y aprovechamiento de los residuos pecuarios" [online]. Revista Mexicana De Ciencias Pecuarias, Vol. 11, supl. 2, p. 107-125, 2020. doi: $10.22319 /$ rmcp.v11s2.4697

[6] I. Gutiérrez, N. Moreno, y D. Montoya. "Mecanismos y regulación de la hidrólisis enzimática de celulosa en hongos filamentosos: Casos clásicos y nuevos modelos" [On line]. Revista Iberoamericana de Micología Vol. 32, núm. 1, 2015. doi: 10.1016/j.riam.2013.10.009. Disponible en: http://www.elsevier.es/es-revis ta-revista-iberoamericana-micologia-290-arti culo-mecanismos-regulacion-hidrolisis-enzi matica-celulosa-S113014061400013

[7] S. Diego. "Application of the Direct Quadrature Method of Moments for the modelling of the enzymatic hydrolysis of cellulosic substrates" [online]. Chemical Engineering Science, Vol. 149, p. 1-20, 2015. doi: 10.1016/j.ces.2016.04.029

[8] A. Panchapakesan y N. Shankar. "Fungal Cellulases: An Overview. In New and Future Developments in Microbial Biotechnology and Bioengineering: Microbial Cellulase System Properties and Applications [online] 2016. doi: 10.1016/B978-0-444-63507-5.00002-2

[9] J. Lee, J. Kim, H. Jang, M. Lee, y J. Park, "Sequential dilute acid and alkali pretreatment of corn stover: Sugar recovery efficiency and structural characterization", [online]. Tecnología ambiental, Vol. 182, p. 296-301, 2015.
[10] A. García, C. Cara, M. Moya, J. Rapado, J. Puls, E. Castro, y C. Martín, "Dilute sulphuric acid pretreatment and enzymatic hydrolysis of Jatropha curcas fruit shells for ethanol production",[online]. Industrial crops and products, Vol. 53, p.148-

[11] M. Resch, J. Baker y S. Decker,"Low Solids Enzymatic Saccharification of Lignocellulosic Biomass", NREL, Denver, USA 2015; TechnicalReport NREL/TP-5100-63351, 2015.

[12] Merk. "Celulasa de Aspergillus niger" [En línea]. USA: 2018.

[13] R. Ávila, B. Rivas, R. Hernández y M. Chirinos, "Contenido de azúcares totales, reductores y no reductores en Agave cocui Trelease" [online]. Multiciencias, Vol. 12, núm. 2, p. 129-135, 2012.

[14] M. Megías, P. Molist y M. Pombal, Atlas de histología vegetal y animal, [online]. Universidad de Vigo, España, 2018.

[15] H. Zhang, S. Wu y J. Xie. "Evaluation of the effects of isolated lignin on enzymatic hydrolysis of cellulose", Enzyme and Microbial Technology, Vol. 101, p. 44-50. Junio, 2017.

[16] O. Di Marco, "Estimación de la Calidad de los forrajes", [online]. Producir XXI, Bs. As., 20(240), p. 24-30, Unidad Integrada Balcarce INTA, 2011.

[17] [ E. Greene, M. Himmel, G. Beckham y Z. Tan. "Glycosylation of Cellulases: Engineering Better Enzymes for Biofuels," Advances in Carbohydrate Chemistry and Biochemistry, Vol. 72, 2015.

[18] N. López, A. Cárdenas y R. Zambrano. "Evaluación de pretratamientos químicos para la hidrólisis enzimática de residuos lignocelulósicos de yuca (Manihot esculenta Crantz)". Reda$l y c$, no. 69, p. 317, 2013.

[19] L. Lucero "Influencia de la hidrólisis enzimática y de la fermentación en el material lignocelulósico de las cáscaras de plátano de las variedades bellaco, inguiri e isla". Tesis de 
ingeniería, Universidad Nacional Pedro Ruíz Gallo, Perú, 2019.

[20] E. Palmqvist, B. Hahn-Hägerdal. "Fermentation of lignocellulosic hydrolysates. II: inhibitors and mechanisms of inhibition. Bioresource Technology, Vol. 74, p. 25-33, 2000.

[21] A. Paniagua. "Degradación de material lignocelulósico, evaluación de pretratamientos químicos e hidrólisis enzimáticas para la obtención de alcoholes por fermentación. Tesis doctoral, Universidad de León, España. 2020.

[22] B. Behera, B. Sethi, R. Mishra, S. Dutta y H. Thatoi. "Microbial cellulases - Diversity and biotechnology with reference to mangrove environment: A review". Journal of Genetic Engineering and Biotechnology, Vol. 15, p. 197-210, 2017.

[23] C. Chandler, N. Villalobos, E. Gonzales, E. Arenas, Z. Mármol, J. Ríos y C. Aiello, "Hidrólisis ácida diluida en dos etapas de bagazo de caña de azúcar para la producción de azúcares fermentables", [online]. Multiciencias, Vol. 12, núm. 3, p. 245-253, 2012.

[24] K. Philomena, N. Christian, T. Joseph. "Hidrólisis enzimática y fermentación de cáscaras de plátano: optimización y estudios cinéticos", Advances in Chemical Engineering and Science, Vol. 6, p. 216-235, 2016.

[25] D. Narciso. "Estudio de la producción de azúcares fermentables a partir de la celulosa contenida en desechos agrícolas o industriales, por medio de una hidrólisis enzimática", [online]. Tesis de Ingeniería Química, Universidad Central de Venezuela, 2007. Disponible en: http://saber.ucv.ve/bitstream/123456789/131 0/1/TESIS2.pdf

[26] L. Niño, A. Acosta y R. Gelves. "Evaluación de pretratamientos químicos para la hidrólisis enzimática de residuos lignocelulósicos de yuca (Manihot esculenta Crantz)", Revista Facultad de Ingeniería Universidad de Antioquia, núm. 69, p. 317-326, 2013. 